\title{
Integrating Oral and Systemic Health: Innovations in Transdisciplinary Science, Health Care and Policy
}

\author{
Martha Somerman ${ }^{1,2 *}$ and Wendy E. Mouradian ${ }^{3,4}$ \\ ${ }^{1}$ National Institute of Arthritis and Musculoskeletal and Skin Diseases, National Institutes of Health, Bethesda, MD, \\ United States, ${ }^{2}$ National Institute of Dental and Craniofacial Research, National Institutes of Health, Bethesda, MD, \\ United States, ${ }^{3}$ School of Dentistry, University of Washington, Seattle, WA, United States, ${ }^{4}$ The Santa Fe Group, New York, \\ NY, United States
}

Keywords: integration, health systems, medicine, dentistry, oral - general health, health policy

\section{SETTING THE STAGE}

The newly launched (June 1, 2020) Frontiers in Dental Medicine (FDMED) has a bold mission and vision focused on ensuring that dental, oral, and craniofacial health and diseases are understood in the context of the whole body. FDMED advocates a transdisciplinary, systems-based approach ${ }^{1}$ to solving basic, clinical, and translational challenges in order to improve oral and overall health outcomes for all communities. FDMED will accomplish this by attracting rigorous, innovative investigations, and commentaries from researchers where dental-oral health is an integral part of investigations into underlying health mechanisms to include biological, behavioral and social factors, clinical approaches, tools and technologies and health care delivery models/policies. We envision that the information disseminated in Frontiers in Dental Medicine and Frontiers in Oral Health will stimulate further work and ultimately contribute to the development of evidence-based, cost-effective disease prevention and health care strategies applicable across diverse populations.

OPEN ACCESS

Edited by: Josette Camilleri,

University of Birmingham, United Kingdom

Reviewed by:

William Giannobile, Harvard School of Dental Medicine, United States

*Correspondence: Martha Somerman msomerman13@gmail.com; martha.somerman@nih.gov

Received: 26 August 2020 Accepted: 22 September 2020 Published: 02 November 2020

Citation:

Somerman M and Mouradian WE (2020) Integrating Oral and Systemic Health: Innovations in Transdisciplinary

Science, Health Care and Policy.

Front. Dent. Med. 1:599214.

doi: 10.3389/fdmed.2020.599214

\section{THE GRAND CHALLENGE}

The Grand Challenge for this field is to make this vision a reality, creating innovations for health by integrating oral health across science and other health sectors.

\section{INTENSIFYING COLLABORATIVE RESEARCH EFFORTS AND ACCELERATING SCIENCE TRANSLATION}

Why is a collaborative approach important? Much research and clinical practice lack a collaborative approach across disciplines and professions. This is very evident in the separation of dental-oral considerations from the rest of overall health across much of the health enterprise-from wet bench science to delivery of healthcare itself. The consequences are devastating - a siloed (and sometimes stalled) approach to the science, and ineffective, fragmented, and costly delivery systems. Added to this, are siloed approaches even within a given profession e.g., subspecialties within medicine and dentistry. This has resulted in a of lack of translation of basic science to clinical care, and to policies which can reach communities to achieve real advances in health. This separation has also led to the

\footnotetext{
${ }^{1}$ For the purpose of this Grand Challenge, recognizing that "systems-based approach" means different things to different groups, we consider systems-based approaches as defined by NIH in 2011 and in concert with our focus on integration of oral with within total health, "an approach in biomedical research to understanding the larger picture-be it at the level of the organism, tissue, or cell-by putting its pieces together. It's in stark contrast to decades of reductionist biology, which involves taking the pieces apart." https://irp.nih.gov/catalyst/v19i6/systems-biology-as-defined-by-nih.
} 
general perception that oral and dental health are somehow less important to overall health and well-being, and hence they are not prioritized in professional training, public policy or healthcare delivery. For underserved communities, this inattention to and lack of resources for oral health have resulted in significant and consequential disparities in oral health and access to care beyond those seen in other areas of healthdisparities which could, in part, be ameliorated by integrated approaches to science, policy, and healthcare (1-9).

There are potentially large pay offs in knowledge and public health to be gained from interrogating the dental-oralcraniofacial region in the context of the whole body. Of urgency in the current SARS-CoV-2 pandemic is an understanding of how the host response and inflammatory networks result in differences in disease manifestations across the body (10). For example, there is need for a deeper understanding of how the virus affects taste and smell receptors. There is also the potential of new salivary diagnostics to identify virus in saliva of infected individuals, and mouth rinses for preventing infection and/or disease progression. Meanwhile oral aerosol generation has been a critical area for investigating disease transmission (11-16).

Broader questions such as why certain diseases manifest themselves differently (or similarly) in specific tissues or organs or why are there are differences (or similarities) in the responsiveness of specific tissues to a given environmental factor can also be revelatory. For example, research led by diverse teams, focused on determining the cause for severe microcephaly in infants exposed to Zika virus, in utero, demonstrated that the virus infects neural crest cells $(17,18)$. The area of craniofacial research and clinical practice is one that validates the value of trans-disciplinary teams advancing evidence-based research with application to the clinic.

As the mouth can be both a window and gateway into the body, systemic conditions as well as side effects of medical therapies may present early with oral manifestations. Unfortunately, the disconnects between the dental-oral region and the body have hampered recognition of these signs and symptoms. It is our hope that this Grand Challenge, and the Research Topic to follow, will escalate collaborative efforts at the research, clinical and health system levels. New investigations show the potential of such collaborations. In recent years the immune-microbiome complex has become an area of intense investigation revealing the effects of a healthy vs. a diseased microbiome from various regions, e.g., mouth, skin, gastrointestinal tract, urogenital tract, on the host-immune response $(19,20)$. It has long been known that microbes associated with the oral cavity are active in distant parts of the body and can be etiologic in bacterial endocarditis, joint infections, brain abscesses, but newer studies reveal the potential for certain oral bacteria to colonize the gut. For example, Klebsiella, can induce an inflammatory response in the gut, but not in the oral mucosa (21), while Fusobacterium nucleatum, an oral bacterium associated with severe periodontal disease, is linked to colon cancer (22). Porphyromonas gingivalis, a keystone pathogen in chronic periodontal disease, has been identified in amyloid plaques of individual's with Alzheimer's disease (23).
The potential for drugs to affect the dental-oral-craniofacial (DOC) complex is vast. As one example, bisphosphonates and other antiresorptive agents, commonly used to treat osteoporosis and certain cancers, have resulted in osteonecrosis of the jaw; understanding this complication has been critical for elucidating the dynamics of bone metabolism-and for informing patients taking these drugs of the attendant oral health risks (24). There are also oral conditions/syndromes/diseases which are not diagnosed in a timely fashion due to the lack of collaborative approaches, and where delay can be disastrous. One example is cancers, where oral cancer detection has taken on added importance with the rise of oral-pharyngeal cancers in younger persons, many associated with HPV. When HPV vaccines were first advocated, it was primarily for prevention of cervical cancer; it took careful examination of oral pathologies to reveal this potentially devastating disease manifestation in the oral cavity $(25,26)$.

As these few examples illustrate, the complex nature of health determinants requires broad collaborations across disciplines and sectors to gain scientific data to inform clinical care and policy decisions. As an example of a downstream effect, the high incidence of periodontal infections in individuals with Diabetes have led many U.S. insurance companies to offer additional dental care for their patients with this disease. Other downstream outcomes include physicians advising patients of the oral health impacts of antiresorptive therapies, and dentists counseling their patients on the HPV vaccine.

\section{THE BODY GETS IT, WHY DON'T WE? CHANGING THE CONTEXT FOR ORAL
HEALTH}

The siloing of dentistry from other health care professions in the U.S. is the result of the historic separation of medicine and dentistry. This precedent has been maintained across almost two centuries [despite calls for better integration in seminal analyses such as the Gies Report (27)], and is now ensconced in the institutions of education/training, in the research enterprise, in financing of healthcare and in delivery models. As such it has had critical consequences for public health and costs of care; the disparities in oral health and access to care under this system have been extensively documented (28).

Less clear have been the steps needed to overcome this divide, given the extent of institutionalization of this separation across health sectors and in public perceptions. Yet, as the science has advanced, the calls for integration of oral health into overall health and of the need for closer alignment of dentistry with medicine have been sounded and have begun to intensify.

The 2000 U.S. Surgeon General's Report on Oral Health (29) and the subsequent National Call to Promote Oral Health (30) recognized the growing evidence of the importance of DOC in overall health. Some 20 years later a second SGROH (planned release later in 2020) will explicitly address the reasons for and challenges of integrating oral health. The NASEM Roundtable on Integrating Oral and General Health through Health Literacy 
Practices extensively documented the many integration efforts underway (e.g., pediatricians providing $\mathrm{F}$ varnishes and other oral health preventive interventions in their offices) (31) and led to promising discussions (32). In 2019 The journal Lancet published a series of articles on the importance of oral health, emphasizing the need for integration, and subsequently launched a Lancet Oral Health Commission (33). Other efforts have been aimed at integrating oral health into non-dental health professional training (34).

The vision of FDMED and this Grand Challenge are aligned with these and other calls for integration across science, policy and healthcare (35). We are also collaborating with other efforts aimed at shifting this paradigm, such as a 2021 Salon being planning by the Santa Fe Group that will also explore innovations needed in the integration of oral and overall health (36).

But much work remains to be done to bring this vision to reality.

\section{MAKING A DIFFERENCE}

To disseminate and catalyze more investigations in this area, FDMED will release a Research Topic specifically calling for submissions responsive to this challenge. The dental-oralcraniofacial field needs not just more research, but studies that reflect an emerging paradigm that delves into the response of dental-oral tissues to genetic and epigenetic modulators, the microbiome and immune surveillance, as well as other kinds

\section{REFERENCES}

1. Weyant R, Watt R. A call for action to improve US oral health care. J Am Dent Assoc. (2020) 151:73-5. doi: 10.1016/j.adaj.2019.12.003

2. The Lancet. Oral health at a tipping point. Lancet. (2019) 394:188. doi: 10.1016/S0140-6736(19)31639-3

3. Peres MA, Macpherson L, Weyant RJ, Daly B, Venturelli R, Mathur MR, et al. Oral diseases: a global public health challenge. Lancet. (2019) 394:249-60. doi: 10.1016/S0140-6736(19)31146-8

4. Watt, RG, Daly B, Allison P, Macpherson L, Venturelli R, Listl S, et al. Ending the neglect of global oral health: time for radical action. Lancet. (2019) 394:261-72. doi: 10.1016/S0140-6736(19)31133-X

5. Vujicic M, Buchmueller T, Klein R. Dental care presents the highest level of financial barriers, compared to other types of health care services. Health Aff. (2016) 35:2176-82. doi: 10.1377/hlthaff.2016.0800

6. Jones JA, Snyder JJ, Gesko DS, Helgeson MJ. Integrated medical-dental delivery systems: models in a changing environment and their implications for dental education. J Dent Educ. (2017) 81:eS21-9. doi: 10.21815/JDE.017.029

7. Glick M, Monteiro da Silva O, Seeberger GK, Xu T, Pucca G, Williams DM, et al. FDI Vision 2020: shaping the future of oral health. Int Dent J. (2012) 62:278-91. doi: 10.1111/idj.12009

8. Atchison KA, Weintraub JA, Rozier RG. Bridging the dental-medical divide: Case studies integrating oral health care and primary health care. J Am Dent Assoc. (2018) 149:850-8. doi: 10.1016/j.adaj.2018.05.030

9. Mossey P. 'Oral health matters': it is time for a culture change in dentistry. $\mathrm{Br}$ Dent J. (2020) 228:829-30. doi: 10.1038/s41415-020-1634-3

10. Kleinstein SE, Nelson KE, Freire M. Inflammatory networks linking oral microbiome with systemic health and disease. J Dent Res. (2020) 99:1131-9. doi: 10.1177/0022034520926126

11. Bescos R, Casas-Agustench P, Belfield L, Brookes Z, Gabaldón T. Coronavirus disease 2019 (COVID-19): emerging and future challenges for dental and oral medicine. J Dent Res. (2020) 99:1113. doi: 10.1177/0022034520932149 of investigations that explicate basic mechanisms underlying clinical conditions such as those discussed above. By attracting researchers focused on a systems-based approach, Frontiers in Dental Medicine will identify where further exploration is needed at the basic, translational and clinical levels, and which clinical and research partnerships are needed to accelerate this science.

In this way Frontiers in Dental Medicine hopes to create exponential growth in our understanding of the underlying mechanisms guiding health and disease that includes the dentaloral-craniofacial region. The ultimate results will be advances in precision healthcare that include dental-oral-craniofacial factors in health and disease. Without a comprehensive and integrated approach to medical science that includes dental and oral health, our public policies cannot provide the best answers to health promotion, disease prevention, early detection and treatment for the most common diseases, as well as for many rare ones.

\section{AUTHOR CONTRIBUTIONS}

Both authors worked together on crafting the concept and preparing the grand challenge.

\section{ACKNOWLEDGMENTS}

Colleagues globally and special thanks to the FDMED staff and specialty editors and the Santa Fe Group.

12. Meng L, Hua F, Bian Z. Coronavirus disease 2019 (COVID-19): emerging and future challenges for dental and oral medicine. J Dent Res. (2020) 99:481-7. doi: 10.1177/0022034520914246

13. Marui VC, Souto M, Rovai ES, Romito GA, Chambrone L, Pannuti CM. Efficacy of preprocedural mouthrinses in the reduction of microorganisms in aerosol: a systematic review. J Am Dent Assoc. (2019) 150:1015-26.e1. doi: 10.1016/j.adaj.2019.06.024

14. Kirk-Bayley J, Sunkaraneni V, Challacombe S. The Use of Povidone Iodine Nasal Spray and Mouthwash During the Current COVID-19 Pandemic May Reduce Cross Infection and Protect Healthcare Workers. SSRN [Preprint] (2020). Available online at: https://ssrn.com/abstract $=3563092$

15. Carrouel F, Conte MP, Fisher J, Gonçalves LS, Dussart C, Llodra JC, Bourgeois D. COVID-19: A recommendation to examine the effect of mouthrinses with $\beta$-cyclodextrin combined with citrox in preventing infection and progression. J Clin Med. (2020) 9:1126. doi: 10.3390/jcm9041126

16. Wyllie AL, Fournier J, Casanovas-Massana A, Campbell M, Tokuyama M, Vijayakumar P, et al. Saliva is more sensitive for SARS-CoV-2 detection in COVID-19 patients than nasopharyngeal swabs. medRxiv [Preprint] (2020). Available online at: https://doi.org/10.1101/2020.04.16.20067835

17. Bayless NL, Greenberg RS, Swigut T, Wysocka J, Blish CA. Zika virus infection induces cranial neural crest cells to produce cytokines at levels detrimental for neurogenesis. Cell Host Microbe. (2016) 20:423-8. doi: 10.1016/j.chom.2016.09.006

18. Gorshkov K, Shiryaev SA, Fertel S, Lin YW, Huang CT, Pinto A, et al. Zika Virus: origins, pathological action, and treatment strategies. Front Microbiol. (2019) 9:3252. doi: 10.3389/fmicb.2018.03252

19. Kitamoto S, Nagao-Kitamoto H, Hein R, Schmidt TM, Kamada N. The bacterial connection between the oral cavity and the gut diseases. J Dent Res. (2020) 99:1021-9. doi: 10.1177/0022034520924633

20. Netea MG, Domínguez-Andrés J, Barreiro LB, Chavakis T, Divangahi M, Fuchs E, et al. Defining trained immunity and its role in health and disease. Nat Rev Immunol. (2020) 20:375-88. doi: 10.1038/s41577-020-0285-6 
21. Atarashi K, Suda W, Luo C, Kawaguchi T, Motoo I, Narushima S, et al. Ectopic colonization of oral bacteria in the intestine drives $\mathrm{T}_{\mathrm{H}} 1$ cell induction and inflammation. Science. (2017) 358:359-65. doi: 10.1126/science.aan4526

22. Mima K, Nishihara R, Qian ZR, Cao Y, Sukawa Y, Nowak JA, et al. Fusobacterium nucleatum in colorectal carcinoma tissue and patient prognosis. Gut. (2016) 65:1973-80. doi: 10.1136/gutjnl-2015-310101

23. Dominy SS, Lynch C, Ermini F, Benedyk M, Marczyk A, Konradi A, et al. Porphyromonas gingivalis in Alzheimer's disease brains: evidence for disease causation and treatment with small-molecule inhibitors. Sci Adv. (2019) 5:eaau3333. doi: 10.1126/sciadv.aau3333

24. Wan JT, Sheeley DM, Somerman MJ, Lee JS. Mitigating osteonecrosis of the jaw (ONJ) through preventive dental care and understanding of risk factors. Bone Res. (2020) 8:14. doi: 10.1038/s41413-020-0088-1

25. D'Souza G, Kluz N, Wentz A, Youngfellow RM, Griffioen A, Stammer E, et al. Oral human papillomavirus (HPV) infection among unvaccinated high-risk young adults. Cancers. (2014) 6:1691-704. doi: 10.3390/cancers60 31691

26. Tang KD, Baeten K, Kenny L, Frazer IH, Scheper G, Punyadeera C. Unlocking the potential of saliva-based test to detect HPV-16-driven oropharyngeal cancer. Cancers. (2019) 11:473. doi: 10.3390/cancers11040473

27. American Dental Education Association ADEAGies Foundation. Gies Report (1926). Available online at: https://www.adea.org/ADEAGiesFoundation/ William-J-Gies-and-Gies-Report.aspx (accessed August, 2020)

28. Northridge ME, Kumar A, Kaur R. Disparities in access to oral health care. Annu Rev Public Health. (2020) 41:513-35. doi: 10.1146/annurev-publhealth-040119-094318

29. National Institutes of Health. 2000 Surgeon General's Report on Oral Health in America. (2000). Available online at: https://www.nidcr.nih.gov/research/ data-statistics/surgeon-general (accessed August, 2020)

30. Office of the Surgeon General (US). National Call to Action to Promote Oral Health. National Institute of Dental and Craniofacial Research (US). NIH Publication No. 03-5303 (2003).

31. Atchison KA, Rozier RG, Weintraub JA. Integrating Oral Health, Primary Care, and Health Literacy: Considerations for Health Professional Practice,
Education and Policy. National Academies Press (US) (2018). Available online at: https://www.nationalacademies.org/our-work/integrating-dentaland-general-health-through-health-literacy-practices-a-workshop

32. Wojtowicz A, Olson S. National Academies of Sciences, Engineering, and Medicine; Health and Medicine Division; Board on Population Health and Public Health Practice; Roundtable on Health Literacy. Integrating Oral and General Health Through Health Literacy Practices: Proceedings of a Workshop. National Academies Press (US) (2019). Available online at: https:// www.nap.edu/read/25468/chapter/1

33. University College London, Institute of Epidemiology and Health Care. Lancet Commission on Oral Health. (2019). Available online at: https:// www.ucl.ac.uk/epidemiology-health-care/research/epidemiology-andpublic-health/research/dental-public-health/lancet-commission-oral-health (accessed August, 2020)

34. Oral Health Nursing Education Program. Available online at: http://ohnep. org/ (accessed August, 2020)

35. National Institute of Dental and Craniofacial Research. NIDCR 2030: Envisioning the Future, Together. (2018). Available online at: https://www. nidcr.nih.gov/research/research-priorities-nidcr-2030 (accessed August, 2020)

36. Santa Fe Group: Improving Lives Through Oral Health. Available online at: https://santafegroup.org/ (accessed August, 2020)

Conflict of Interest: The authors declare that the research was conducted in the absence of any commercial or financial relationships that could be construed as a potential conflict of interest.

Copyright (c) 2020 Somerman and Mouradian. This is an open-access article distributed under the terms of the Creative Commons Attribution License (CC BY).

The use, distribution or reproduction in other forums is permitted, provided the original author(s) and the copyright owner(s) are credited and that the original publication in this journal is cited, in accordance with accepted academic practice. No use, distribution or reproduction is permitted which does not comply with these terms. 